\title{
THE WAY AHEAD IN MENTAL HANDIGAP
}

\author{
By DR G. B. Simon, \\ Consultant Psychiatrist, Lea Castle Hospital, Kidderminster
}

\begin{abstract}
The views I express in this paper are my personal views and not those of either the Department of Health and Social Security or the National Development Group, but they are, nevertheless, based on established services and views expressed to me by colleagues in various parts of the country.

We have been told that, in general terms, Government policy on mental handicap remains as stated in the White Paper Better Services for the Mentally Handicapped of $197 \mathrm{I}$. However, towards the end of 1974 it was felt that its implementation had fallen far behind the targets originally set, and to assist in overcoming this the Secretary of State, in February 1975, announced the setting up of the National Development Group (NDG) and the Development Team for the Mentally Handicapped.
\end{abstract}

The NDG commenced its activities shortly after the official announcement and has since published several widely circulated bulletins and pamphlets. Included in these publications is information on the membership of the Development Group and the Development Team. Although the latter was referred to by the Secretary of State in the original statement, it did not actually become functional until July 1976 . The Team consists of a nucleus of four people - three Associate Directors representing Nursing, Social Work and Administration, with myself as the Director. In addition, a Panel of some forty professionals and others has been set up, which includes representatives of every group of people involved with the mentally handicapped. Panel members are normally seconded for periods of a week to a fortnight to a team to take part in specific exercises and studies.

The Team is independent of the DHSS and serves a number of functions.

I. It provides advice and assistance to health and local authorities on the implementation of policy, the establishment of joint planning and any other aspect of services to the mentally handicapped.

2. It is a major source of information from the field to the DHSS and the NDG so that the views of the field may be taken into account when policy guidelines are provided.

3. The Team has a specific task relating to mentally handicapped children in long-term care, which is to examine and comment on the standard and quality of care provided and to keep the Department and the Secretary of State informed of the standards which are operating. This function is in parallel with that being undertaken by the Health Advisory Service in relation to physically handicapped children. The Health Advisory Service has, since the setting up of the Development Team, relinquished its role in connection with the mentally handicapped in England.

4. In addition, the Team offers advice on mental handicap to Community Health Councils, voluntary bodies and others who seek it, through meetings, attendance at conferences, study days, workshops, etc.

The White Paper of 1971 suggested that many services for the mentally handicapped could and should be provided at District level and generally from small units so that they were more easily accessible to the populations they served. In the past, large hospitals have tended to provide most of the long-term residential care both for the severely subnormal and for others who are only moderately so. It is accepted today that many of the psychiatric needs of the mentally handicapped and their families can be met quite satisfactorily and appropriately through local services and in the home itself, with parents, relatives and staff caring for them in schools, training centres and other facilities taking part.

The use of the large hospital for all mentally handicapped, irrespective of their therapeutic needs, brought about considerable overcrowding and misuse of the hospital. They came to be used as convenient repositories for thousands of people who were admitted for social reasons rather than a need of specialist services.

In the past thirty years, concepts of management and attitudes have altered so that medical and other staff can treat handicapped people at home and use the alternatives that are available in place of residential care.

Comprehensive assessment, the use of medication, the early involvement of parents and relatives in management, structured programmes to improve skills, accompanied by regular follow-up and review, the use of play groups, parent groups, toy libraries and short-term care are now generally accepted as the necessary ingredients of proper management of the mentally handicapped. It is also now accepted

* Summary of a paper read to the Mental Deficiency Section (29 September 1976). 
that if these services can be provided early they will frequently enable a large number to remain in the community.

In many parts of the country such local services for both adults and children have been established, the staff using those facilities which already exist. As a result, many consultants in mental handicap are now operating as members of multi-disciplinary teams, which include the community nurse in mental handicap, clinical psychologist, social worker and others, depending on the age and needs of the patient and his family. In areas where distances from the hospital are great, the working of such teams is facilitated by establishing small units locally from which teams may operate. These units can frequently and economically be established in unused Health Service premises that are conveniently placed to be accessible to populations of 60,000 to 100,000 .

The most constant members of a team will be the specialist in mental handicap, who may serve two or three teams, with the community nurse and social worker, who will usually serve one team. It must be appreciated that every need cannot be met in this manner, and hospitals will continue to provide many of the back-up services to these peripheral units. It will also be necessary for members of the team to be in regular contact with the hospital at which the more sophisticated and specialist services are available, and also maintain contact between its residents and their families who live in the sectors of the catchment area for which they are responsible.

\section{The specialist in mental handicap}

Specialists in mental handicap are all qualified psychiatrists and their role should be mainly in the area of psychiatry concerned with the mentally handicapped themselves and their families. Many are concerned only with the mentally handicapped, but some general psychiatrists are now being involved. Also, in some parts of the country they are trained, in addition, as child psychiatrists, and provide both mental handicap and child psychiatry services.

If community-oriented services are to be effective, consultants' duties must include out-patient clinics at community units, ESN schools, training and other centres, so that parents, teachers, care and training staff can all become directly involved. The establishment of teams will assist in the operation and maintenance of programmes of treatment and management locally in the community unit, at home, school or work centre and also help to maintain regular contact, when necessary, with those families whose relatives and children are attending out-patient clinics. This team is essentially a therapeutic team for those mentally handicapped and their families who require its services, and not for all the mentally handicapped, most of whom are quite adequately dealt with by other agencies.

Hospital returns indicate that many consultants in mental handicap, in association with others, are now offering services along these lines, with results that are quite striking and far more encouraging than the 'once and for all emergency or crisis admission' that operated fifteen or twenty years ago. The involvement of consultants in two or more teams will occupy about five or six sessions, leaving four or five sessions for hospital and other work.

It will also be necessary for hospitals to develop certain specialist services for the mentally handicapped on an Area or sub-Regional basis for groups such as the blind and deaf, behaviourally disturbed children and adults, and those with communication difficulties, since for these the numbers in any one District may be so small that it would make local services uneconomical or even impossible.

\section{Responsibility of the specialist in mental handicap}

The responsibility of every consultant to set up and overview a programme of care for those patients who require the specialized clinical services of a hospital is not in question. There are, however, consultants working single-handed who consider themselves to have an overall responsibility for as many as 1,200 residents, 50 per cent of whom do not require their skills at all. Because of this concept of overall responsibility, they cannot attempt to operate the more appropriate services described above and for which they were trained, and it is therefore not surprising that there is a dearth of new entrants to the specialty. The profession must define a more realistic and specific role for its consultants in mental handicap if the grave shortage we are now experiencing is not to continue and ultimately force change upon us, which would probably abolish altogether mental handicap as a specialty for psychiatrists.

As I have already said, I believe that consultants in mental handicap are essentially psychiatrists who have become experienced in the treatment of psychiatric conditions associated with the mentally handicapped and their development. The mentally handicapped are a heterogeneous group of people, and therefore consultants, if they are to be effective, will need to become familiar with such subjects as genetics, sensory handicap and cerebral palsy, because of their frequent association with mental handicap. It is unreasonable, however, then to suggest that they should be the only source of all advice to the mentally handicapped or have overall responsibility for the management of all mentally 
handicapped persons, whether they require psychiatric treatment or not.

That a consultant psychiatrist in mental handicap is legally responsible for the medical treatment he prescribes, as with other specialists is not denied. But I do not think a consultant can be held legally responsible for the non-medical services which are provided by other agencies.

It is common practice for individual consultants from time to time to develop interests in particular aspects of handicap. This is in keeping with practice in all other professions, both medical and nonmedical, and many will find themselves in demand because they have acquired this experience in treatment and management in specific areas. However, it would be wrong to insist that every consultant should be a specialist in all the associated subjects and be totally responsible for every sphere simply because the patient is mentally handicapped.
I am very much aware that opinion is divided on the role of the specialist in mental handicap in the profession itself, while some are of opinion that it is an unnecessary medical specialty. The latter view can only be the outcome of ignorance, of lack of contact with the mentally handicapped and their families, or of the naive assumption that other professionals will assume responsibility for psychiatric services to them-an opinion which would seem to be based on an emotional approach rather than a serious attempt to provide services that are required. But the psychiatrist specializing in mental handicap must now re-appraise his role in a careful and unprejudiced way. Above all, we must avoid expending time and energy in defending the right of the consultant to adhere to a largely out-dated and irrelevant role while neglecting to define clearly the real and essential functions of the psychiatrist in mental handicap.

\section{REPORTS AND PAMPHLETS}

WHO Working Group on the Future of Mental Hospitals (WHO).

This is a summary of the discussions of a Working Group of twenty experts from thirteen countries, including psychiatrists, public health administrators and others participating in the mental health field. A comprehensive final report is promised later which will identify the participants and the countries from which they emanate.

The Report refers to two WHO publications-the Conference on Comprehensive Psychiatric Services and the Community (1972) and the Working Group on Psychiatry and Primary Medical Care (1973). One wonders how widely these have been circulated and how much they have influenced current opinion.

The Report comments on the shift of emphasis in responsibility for the provision of psychiatric services from hospital to the community and describes all participating countries as developing comprehensive mental health services. "The mental hospital may no longer have a pivotal role in the provision of these services', says the Report, but many of the countries concerned may not have mental hospital beds in significant numbers. The care of long-stay patients, elderly people who are infirm and others who require some form of sheltered living are to be dealt with outside the mental hospital in 'residential care or some other facility', but apart from this now commonplace exhortation there is no concrete suggestion as to what these facilities are to be or how they are to be provided.

The emphasis on primary care fails to note specifically what training and supervision will be necessary to ensure that 'far more tasks for the mentally ill could be carried out by primary care workers'.

The section entitled 'The Changing Role of the Mental Hospital' extols advantages accruing to the mental hospitals from having 'their administration decentralized'; these have not always been obvious to staff and patients. Transfer of management from local to central government was the main advantage conferred by the National Health Service Act (1946) on mental hospitals in the United Kingdom, and a reversal of this policy will not have any of the benefits suggested. The statement that 'a properly integrated mental health system ... does not exist in any European country' should add strength to the plea for pilot studies to be carried out rather than attempting to 'solve' problems by Departmental decree. The Report states that financial obstacles, professional conservatism, public resistance and bureaucratic rigidity slow the process of change and delay hospital closure. Professional conservatism in the United Kingdom (where the private practitioners are not a powerful body) must be the least important of these. 